\title{
Alteration of Pharmacokinetic Parameters for Pentobarbital by Ischemic Stroke and Reversion to Normal by Dexamethasone Treatment
}

\author{
D. J. WEIDLER, M.D., Ph.D., N. S. JALLAD, M.S., K. L. BLACK, and
} J. G. WAGNeR, Ph.D. Miami, Fla., and Ann Arbor, Mich.

CURRENTLY pentobarbital is being used $G$ in clinical trials for brain injury. Smith et al. ${ }^{1}$ reported that $56 \mathrm{mg} / \mathrm{kg}$ pentobarbital, administered prior to the unilateral ligation of the middle cerebral artery (MCA), and light halothane and thiopental, given just before or $15 \mathrm{~min}$ utes after ligation, significantly reduced the amount of brain necrosis in dogs. Hoff et al. ${ }^{2}$ found that when $90 \mathrm{mg} / \mathrm{kg}$ pentobarbital was administered prior to ligation, it reduced the extent of infarction following permanent occlusion of the MCA in baboons. Black et al. ${ }^{3}$ demonstrated that pentobarbital is effective in reducing brain necrosis when administered 2 hours after the onset of ischemic stroke in cats. Smaller doses of pentobarbital also may offer protection in ischemic stroke when combined with other therapeutic maneuvers. For example, inhalation of a gas mixture containing an increased portion of $\mathrm{CO}_{2}$ caused vasodilation of cerebral blood vessels and an increase in cerebral blood flow. In humans, high doses of barbiturates produced deleterious

From the Division of Clinical Pharmacology, University of Miami School of Medicine, Miami, Fla.; The University of Michigan Medical School, Ann Arbor, Mich. (Mr. Black); and the College of Pharmacy, The University of Michigan, Ann Arbor, Mich. (Dr. Wagner). cardiovascular and pulmonary effects, often with a fatal outcome. ${ }^{5}$ However, the mortality of the mongolian gerbil, subjected to a unilateral ligation of the common carotid artery under pentobarbital anesthesia $(60 \mathrm{mg} / \mathrm{kg}$ ), was reduced from 65 per cent to 23 per cent by large doses of dexamethasone $(5 \mathrm{mg} / \mathrm{kg}$ ) given intraperitoneally immediately after surgery and again after 24 hours. $^{6}$

In a previous study, we observed that cats subjected to left middle cerebral artery (LMCA) occlusion remained anesthetized much longer with pentobarbital anesthesia than cats given the same dose of pentobarbital but not subjected to LMCA occlusion.3 Furthermore, we had observed that cats subjected to LMCA occlusion and received both pentobarbital and dexamethasone remained anesthetized for approximately the same length of time as control (sham-operated) cats treated with the same dose of pentobarbital. ${ }^{8} \mathrm{We}$ suspected that these observed differences might be due to an alteration of the pharmacokinetics for pentobarbital under these conditions. In the present study, we determined the effect of acute ischemic stroke in the cat on the pharmacokinetic variables for pentobarbital with and without the concurrent administration of 
dexamethasone. These findings were compared with the pharmacokinetic parameters for pentobarbital from control (sham-operated) cats. The pharmacokinetics for pentobarbital in normal healthy cats recently were described by Wagner et al. ${ }^{7}$ and were compared with that in man. ${ }^{8-10}$

\section{Material and Methods}

Eighteen healthy adult cats, weighing between 2.2 and $4.2 \mathrm{~kg}$, were obtained from the University Animal Care Facility and utilized in the present study. Prior to the surgical procedure, animals were fed once daily with Purina Cat Chow and water ad libitum.

During the three days before surgery was performed, vital signs were obtained periodically and behavior was assessed to assure that the animals were healthy. During the surgical procedure, cats were paralyzed with succinylcholine and maintained on a Harvard apparatus respirator (Model 607). Both femoral veins and a branch of the femoral artery were cannulated under local anesthesia with $2 \%$ lidocaine. Femoral arterial pressure was recorded continuously on a Grass polygraph (Model 7). The mean arterial pressure was maintained at $105 \mathrm{~mm} \mathrm{Hg}$ or greater by replacement of all lost blood with blood from donor cats. ECG leads were implanted under the skin; animals were placed in a reclining position and were alternated from side to side at hourly intervals. During experiments and during surgery, cardiac rate and rhythm were observed directly on a Tektronix physiological monitor (Type 410), and lead II of the ECG was recorded continuously on a Holter monitor electrocardiocorder (Avionics Model 400). These ECG records subsequently were reviewed by passing the magnetic tapes through an Avionics composite electrocardioscanner (Model 650).
Acute focal cerebral ischemia was produced in both experimental stroke groups by ligation of the LMCA, utilizing a modification of the method of Sundt and Waltz. ${ }^{11}$ In the control group, the LMCA was exposed surgically but ligation was omitted. In each group, sodium pentobarbital was administered as an intravenous bolus at a dose of $50 \mathrm{mg} / \mathrm{kg}$. To neutralize the highly basic pentobarbital, a predetermined amount of hydrochloric acid was injected at the same time as the pentobarbital but in a different venous cannula. Respiration was supported during the surgical procedure and continued after ligation of the LMCA for the entire 24-hour experimental period or until spontaneous respiration occurred. The three experimental groups differed in management as follows:

Group I-Sham operation with sodium pentobarbital administration. The LMCA in these cats was exposed; however, ligation was omitted.

Group II-Ischemic stroke with sodium pentobarbital administration. Acute cerebral ischemia was produced by surgical ligation of LMCA.

Group III-Ischemic stroke with sodium pentobarbital and dexamethasone administration. LMCA ligation was completed as for group II. However, $4 \mathrm{mg} / \mathrm{kg}$ dexamethasone was administered intravenously prior to the production of ischemic stroke and every 6 hours thereafter for the entire 24-hour experimental period.

Physiological saline was administered intravenously throughout each experiment to replace fluid losses, and hematocrits were maintained in the range of 26 to $40 \%$; the normal range of hematocrits for cats is 24 to $45 \% .^{12}$ Arterial blood gases were measured hourly during the 24-hour experimental pe-

The Journal of Clinical Pharmacology 
riod and were maintained within the following ranges: $P_{a} \mathrm{D}_{2}, 100 \pm 25 \mathrm{~mm} \mathrm{Hg}$; $P_{a} \mathrm{CO}_{2}, 28 \pm 15 \mathrm{~mm} \mathrm{Hg} ; \mathrm{pH}, 7.40 \pm 0.05$. Rectal temperatures were maintained in the range of 100 to $102^{\circ} \mathrm{F}$; the normal range for cats is 100.4 to $102.2^{\circ} \mathrm{F}^{13}$

In cats of the two experimental groups that were subjected to ischemic stroke, brain lesions caused by the occlusion of LMCA were verified by a previously described procedure. ${ }^{3}$ Verification was based on gross inspection of brain slices and on histological study of hematoxylinand eosin-stained brain sections. The margin between infarcted and healthy tissue was verified with light microscopy.

Arterial blood samples (2 ml) were obtained at $0.083,0.17,0.33,0.5,0.75,1.0$, $1.5,2,3,4,5,6,8,10,12,14,16,20$, and 24 hours after the intravenous administration of pentobarbital. The blood samples were placed in tubes containing heparin as the anticoagulant. Each sample of blood was centrifuged immediately after collection at $2000 \mathrm{rpm}$ for $10 \mathrm{~min}$ utes. The plasma was frozen and stored in the frozen state until just prior to assay. The plasma pentobarbital concentrations were determined utilizing the following gas-chromatographic method. Plas$\mathrm{ma}(0.5 \mathrm{ml})$ was acidified with $0.5 \mathrm{ml}$ $1.0 \mathrm{~N}$ hydrochloric acid, and mephobarbital solution was added as internal standard. Plasma was extracted with $6 \mathrm{ml}$ diethyl ether. The ether layer was dried over anhydrous sodium sulfate and then evaporated to dryness under nitrogen. The residue was taken up in 200 to 300 $\mu \mathrm{l}$ ether, and 1 to $6 \mu \mathrm{l}$ of the solution was injected into the gas chromatograph. The column was packed with $3 \%$ OV-17 on Gas Chrom Q, 100/120 mesh. Operating conditions were as follows: column temperature, $186^{\circ} \mathrm{C}$; injector temperature, $240^{\circ} \mathrm{C}$; detector temperature, $240^{\circ}$ $\mathrm{C}$; nitrogen flow rate, $30 \mathrm{ml} / \mathrm{min}$; hydrogen flow rate, $14 \mathrm{ml} / \mathrm{min}$; air flow rate,
$145 \mathrm{ml} / \mathrm{min}$. The retention times were 2.7 and 6.5 minutes for pentobarbital and mephobarbital, respectively. Determinations are reported in units of micrograms pentobarbital acid per milliliter plasma.

The plasma pentobarbital concentration-time data were processed with the Fortran IV computer program CSTRIP ${ }^{14}$ in order to obtain the initial polyexponential parameter estimates. These estimates were then improved by subjecting them to a nonlinear least-squares analysis by the use of the program NONLIN. ${ }^{16}$ The $t$-test was utilized to determine significant differences between parameters of the experimental stroke groups and the control group.

\section{Results}

The intravenous bolus of sodium pentobarbital $(50 \mathrm{mg} / \mathrm{kg})$ was administered simultaneous with ligation of the LMCA in the two experimental groups (simulated ligation in the control group). The plasma pentobarbital concentration was determined as a function of time over the subsequent 24 hours. This relationship was best described in most cats by the sum of two exponential terms, where the plasma concentration $\left(C_{p}\right)$ is presented as follows:

$$
C_{p}=A \mathrm{e}^{-\alpha t}+B \mathrm{e}^{-\beta t}
$$

In eqs. (1) and (2), $\alpha>\beta$. It previously had been demonstrated by us that at the pentobarbital dose used in the present study the pharmacokinetics for pentobarbital in cats are linear. ${ }^{7}$ Therefore, the simple equations which apply to linear systems were used in the present study for calculations of pharmacokinetic parameters. ${ }^{16}$ Equation (2) was used for calculation of the total area under the plasma pentobarbital concentration-time curve from zero to infinite time $(A U C)^{17}$ :

$$
A U C=\frac{A}{\alpha}+\frac{B}{\beta}
$$


WEIDLER, JALLAD, BLACK, ET AL.

TABLE I

Mean Values of Pharmacokinetic Variables for Pentobarbital in All Three Experimental Groups ( $N=6$ in Each Group)*

\begin{tabular}{lcccc}
\hline Group & $\begin{array}{c}\text { Area under } \\
\text { the curve } \\
(\mu \mathrm{g} \cdot \mathrm{hr} / \mathrm{ml})\end{array}$ & $\begin{array}{c}\text { Plasma } \\
\text { clearance } \\
(\mathrm{ml} / \mathrm{min}-\mathrm{kg})\end{array}$ & $\begin{array}{c}\text { Elimination } \\
\text { rate } \\
\text { constant** } \\
(\mathrm{hr}-1)\end{array}$ & $\begin{array}{c}\text { Volume of } \\
\text { distribution } \\
(\mathrm{l} / \mathrm{kg})\end{array}$ \\
\hline I, Control (sham-operated) & 536 & 1.20 & 0.0596 & 1.22 \\
II, Stroke alone & $(50)$ & $(0.244)$ & $(0.0156)$ & $(0.0830)$ \\
III, Stroke and dexamethasone & 2140 & 0.462 & 0.0290 & 0.955 \\
& $(910)$ & $(0.260)$ & $(0.0126)$ & $(0.244)$ \\
& 850 & 1.10 & 0.0682 & 1.02 \\
& $(369)$ & $(0.435)$ & $(0.0336)$ & $(0.157)$ \\
\hline
\end{tabular}

* Value in parentheses is S.D.

* The half-lives for groups I, II, and III were 12.3, 23.9, and 10.2 hours, respectively.

Equation (3) was used for calculation of the clearance of pentobarbital from the plasma $\left(C l_{p}\right)$, where $D$ is a single intravenous dose:

$$
C l_{p}=\frac{D}{A U C}
$$

From $C l_{p}$ and the rate constant $\beta$, eq. (4) was utilized to calculate the volume of distribution of pentobarbital $\left(V_{d}\right)^{16}$ :

$$
\nabla_{d}=\frac{C l_{p}}{\beta}
$$

The values of the pharmacokinetic variables for pentobarbital in each cat in this study were obtained by computer analysis and calculations with eqs. (2), (3), and (4).

The mean values of pharmacokinetic parameters $A U C, C l_{p}, \beta$, and $\nabla_{d}$ for pentobarbital in the two experimental stroke groups and in the control (sham-operated) group are presented in Table I. Statistical comparisons of these mean values utilizing the $t$-test are presented in Table II. The $A U C$ in group II (stroke alone) is significantly larger than that in groups I (control) and III (stroke plus dexamethasone administration). There is no significant difference in $A U C$ between groups I and III. The plasma clearance and elimination rate constant for pento-

TABLE II

Statistical Comparisons of Mean Values of Pharmacokinetic Variables Among the Three Experimental Groups*

\begin{tabular}{ccccc}
\hline $\begin{array}{c}\text { Groups under } \\
\text { comparison }\end{array}$ & $\begin{array}{c}\text { Area under } \\
\text { the curve } \\
(\mu \mathrm{g} \cdot \mathrm{hr} / \mathrm{ml})\end{array}$ & $\begin{array}{c}\text { Plasma } \\
\text { clearance } \\
(\mathrm{ml} / \mathrm{min}-\mathrm{kg})\end{array}$ & $\begin{array}{c}\text { Elimination } \\
\text { rate constant } \\
(\mathrm{hr}-1)\end{array}$ & $\begin{array}{c}\text { Volume of } \\
\text { distribution } \\
(\mathrm{l} / \mathrm{kg})\end{array}$ \\
\hline I and II & $P<0.01$ & $P<0.002$ & $P<0.01$ & $P<0.05$ \\
II and III & $P<0.01$ & $P<0.01$ & $P<0.05$ & $P>0.5$ \\
I and III & $P>0.1$ & $P>0.5$ & $P>0.5$ & $P<0.05$ \\
\hline
\end{tabular}

- Actual data are in Table I. 
barbital are significantly smaller in group II than in groups I and III; there are no significant differences in $C l_{p}$ and $\beta$ between groups I and III. The volume of distribution of pentobarbital is significantly smaller in groups II and III than in group I; there is no significant difference in $V_{d}$ between groups II and III.

The similarities between groups I and III in $A U C$ and $\beta$ and the obvious difference of group II from groups I and III in these parameters are readily seen in Fig. 1. The slope of the plasma pentobarbital concentration-time curve is markedly decreased by the presence of acute ischemic stroke. However, when dexamethasone is administered prior to the onset of ischemic stroke, the slope of the plasma pentobarbital concentration-time curve is not different from that of a control (sham-operated) animal.



Fig. 1. Semilogarithmic plot of plasma pentobarbital concentration vs. time in selected representative animals from each of the three experimental groups: (๑) normals, group I; (O) stroke and dexamethasone, group III; () stroke only, group II.
Certain physiological parameters were measured throughout the experiments to determine if they remained within normal limits or if there were any differences between experimental groups. Arterial blood pressures, blood gases, and hematocrits, measured before pentobarbital administration and 12 and 24 hours after pentobarbital administration, are presented in Table III. There is a modest elevation in mean arterial blood pressure before pentobarbital administration in group I and at 12 hours after pentobarbital administration in groups $\mathrm{I}$ and II; the normal range for arterial blood pressure in adult cats is 77 to $123 \mathrm{~mm} \mathrm{Hg.}{ }^{18}$ However, when tested by $t$-test, there was no significant difference at any time among the experimental groups in regard to the magnitude of the blood pressure. There were no significant differences among the experimental groups in any of the blood gas measurements except in the $P_{a} \mathrm{CO}_{2}$ at 12 and 24 hours. At 12 hours after dosing, groups II and III had decreased $P_{a} \mathrm{CO}_{2}$ values, and at 24 hours only group III had a decreased $P_{a} \mathrm{CO}_{2}$. Hematocrits in all groups remained in the normal range throughout the duration of the experiment. No significant cardiac arrhythmias were seen in any of the experimental animals. Cerebral infarction was verified histologically in all animals of groups II and III. In summary, it appeared that none of the measured physiological parameters helped to elucidate the mechanism by which ischemic stroke altered the pharmacokinetic parameters for pentobarbital.

\section{Discussion}

This study demonstrated that acute ischemic stroke significantly alters the values of the following pharmacokinetic parameters for pentobarbital : $A U C, C l_{p}$, $\beta$, and $V_{d}$. Ischemic stroke caused both a decreased clearance and a decreased vol- 
WEIDLER, JALLAD, BLACK, ET $\triangle L$.

TABLE III

Mean Arterial Blood Pressure, Blood Gases, and Hematocrit Before the Administration of Pentobarbital and at 12 and 24 Hours After the Administration of Pentobarbital*

\begin{tabular}{|c|c|c|c|c|c|c|}
\hline $\begin{array}{c}\text { Hours } \\
\text { after } \\
\text { pentobarbital }\end{array}$ & Group & $\begin{array}{c}\text { Arterial BP } \\
(\mathbf{m m ~} \mathbf{H g})\end{array}$ & $\begin{array}{c}P_{\mathrm{a}} \mathrm{O}_{\boldsymbol{q}} \\
(\mathrm{mm} \mathrm{Hg})\end{array}$ & $\begin{array}{c}\mathrm{P}_{\mathrm{c}} \mathrm{CO}_{2} \\
\left(\mathrm{~mm} \mathrm{H}_{\mathrm{g}}\right)\end{array}$ & pH & $\begin{array}{l}\text { Hemato- } \\
\text { crit (\%) }\end{array}$ \\
\hline \multirow[t]{3}{*}{0} & I & $\begin{array}{l}133^{* *} \\
(9.3)\end{array}$ & $\begin{array}{c}84 \\
(4.1)\end{array}$ & $\begin{array}{c}26 \\
(2.4)\end{array}$ & $\begin{array}{c}7.39 \\
(0.06)\end{array}$ & $\begin{array}{c}29 \\
(6.9)\end{array}$ \\
\hline & II & $\begin{array}{l}118 \\
(19)\end{array}$ & $\begin{array}{c}89 \\
(7.3)\end{array}$ & $\begin{array}{c}20 \\
(7.2)\end{array}$ & $\begin{array}{c}7.39 \\
(0.04)\end{array}$ & $\begin{array}{c}32 \\
(3.1)\end{array}$ \\
\hline & III & $\begin{array}{c}122 \\
(5.8)\end{array}$ & $\begin{array}{c}83 \\
(16)\end{array}$ & $\begin{array}{c}27 \\
(5.2)\end{array}$ & $\begin{array}{c}7.38 \\
(0.08)\end{array}$ & $\begin{array}{c}31 \\
(1.5)\end{array}$ \\
\hline \multirow[t]{3}{*}{12} & I & $\begin{array}{l}124^{* *} \\
(25)\end{array}$ & $\begin{array}{c}80 \\
(5.6)\end{array}$ & $\begin{array}{c}25 \\
(4.0)\end{array}$ & $\begin{array}{c}7.35 \\
(0.03)\end{array}$ & $\begin{array}{c}34 \\
(2.2)\end{array}$ \\
\hline & II & $\begin{array}{l}126^{* *} \\
(26)\end{array}$ & $\begin{array}{c}86 \\
(12)\end{array}$ & $\begin{array}{c}15 \\
(2.6)\end{array}$ & $\begin{array}{c}7.39 \\
(0.08)\end{array}$ & $\begin{array}{c}36 \\
(3.1)\end{array}$ \\
\hline & III & $\begin{array}{c}122 \\
(5.8)\end{array}$ & $\begin{array}{c}78 \\
(7.6)\end{array}$ & $\begin{array}{c}16 \\
(3.2)\end{array}$ & $\begin{array}{c}7.35 \\
(0.03)\end{array}$ & $\begin{array}{c}31 \\
(2.5)\end{array}$ \\
\hline \multirow[t]{3}{*}{24} & $\mathbf{I}$ & $\begin{array}{r}121 \\
(18)\end{array}$ & $\begin{array}{c}93 \\
(16.7)\end{array}$ & $\begin{array}{c}24 \\
(5.3)\end{array}$ & $\begin{array}{c}7.36 \\
(0.04)\end{array}$ & $\begin{array}{c}33 \\
(3.1)\end{array}$ \\
\hline & II & $\begin{array}{c}113 \\
(22)\end{array}$ & $\begin{array}{l}104 \\
(17)\end{array}$ & $\begin{array}{c}23 \\
(4.7)\end{array}$ & $\begin{array}{c}7.39 \\
(0.03)\end{array}$ & $\begin{array}{c}33 \\
(1.1)\end{array}$ \\
\hline & III & $\begin{array}{l}122 \\
(15)\end{array}$ & $\begin{array}{c}82 \\
(11)\end{array}$ & $\begin{array}{c}13 \\
(0.5)\end{array}$ & $\begin{array}{c}7.36 \\
(0.03)\end{array}$ & $\begin{array}{c}35 \\
(2.2)\end{array}$ \\
\hline
\end{tabular}

- Value in parenthesis is S.D.

** Elevated above normal range.

ume of distribution of pentobarbital. These two factors together account for the significantly increased $A U C$ in cats subjected to ischemic stroke alone (group II). Plasma clearance is decreased because both the elimination rate constant and volume of distribution are decreased; this is true because plasma clearance is the product of $\beta$ and $V_{d}$ [see eq. (4)].

The mechanism of change in pharmacokinetic parameters probably has its basis in marked cardiovascular changes which are secondary to ischemic stroke. We previously have demonstrated that myocardial damage is secondary to ischemic stroke, as evidenced by the presence in plasma of myocardial isoenzyme (MB band) of creatine phosphokinase
(CPK).19 Furthermore, we have shown that cardiac output decreases and circulating catecholamine concentrations increase secondary to the onset of ischemic stroke. $^{20}$ We previously have described a shock-like syndrome of cardiovascular origin secondary to the combined effects of ischemic stroke and pentobarbital administration. ${ }^{8}$

Benowitz and Meister ${ }^{21}$ have reviewed the effects of congestive heart failure and increased sympathetic nervous system activity (both of which can occur secondary to ischemic stroke) on the pharmacokinetics of several drugs. The consequences of these two conditions are a decreased volume of distribution of the drug, a change in the blood flow pattern 
to various organs, and decreased hepatic clearance of the drug. The decrease in volume of distribution may be due to shunting of blood away from organs that are not vital and to decreased uptake of drug by more slowly perfused tissues. ${ }^{21}$

It has been demonstrated that pentobarbital is metabolized by hepatic microsomes. ${ }^{22}$ It is in the latter subcellular fraction where hydroxylation of the side chain of pentobarbital occurs to produce inactive oxidized pentobarbital. ${ }^{22}$ For drugs metabolized by the liver, systemic drug clearance is generally considered to be hepatic blood-flow dependent only with those drugs that have high hepatic intrinsic clearances. ${ }^{23}$ Pentobarbital does not have a high intrinsic clearance. However, diseases that markedly alter the circulation of the liver can compromise the function of the liver and decrease the intrinsic clearance for a drug. ${ }^{23}$ This chain of events could partially explain the decreased plasma clearance of pentobarbital after the onset of ischemic stroke.

One further explanation for the prolongation of the half-life of pentobarbital after the onset of ischemic stroke emerges from the theory of Brodie et al. ${ }^{24}$ That is, the rate of uptake of pentobarbital by fat tissue determines the length of action of the drug; in other words, the more rapid the uptake of pentobarbital by fat tissue, the shorter is the anesthetic effect of the drug. One may substitute "plasma concentration" for "anesthetic effect" in this theory and apply it to the present problem. Thus, the elimination rate constant may be dependent in part on the rate of uptake of the drug by fat tissue. This hypothesis is supported by the observation of Kitagawa ${ }^{25}$ that the pentobarbital concentration in fat tissue of the cat increased by 128 per cent from the second hour to the sixth hour after intraperitoneal injection of $70 \mathrm{mg} / \mathrm{kg}$. That is, the pentobarbital concentration in fat tissue increased while the plasma pentobarbital concentration decreased. Consequently, if the cardiac output decreases as a result of the onset of ischemic stroke and results in decreased blood flow to fat tissue and a decreased rate of uptake of pentobarbital by fat tissue, then the value of the apparent elimination rate constant $(\beta)$ would be less than normal. This would result in a prolongation of the half-life of pentobarbital.

The mechanism of action of dexamethasone in the apparent reversion to normal of the altered values of the pharmacokinetic parameters for pentobarbital after the onset of ischemic stroke are similarly speculative but are supported by some reported observations. We have already indicated that the combined effect of ischemic stroke and high-dose pentobarbital treatment may result in the tendency toward a circulatory shocklike state. ${ }^{3}$ Harrison and Russel reported that dexamethasone was effective in decreasing mortality in gerbils subjected to ischemic stroke and in which pentobarbital had been administered. ${ }^{26}$ The mechanism of action of dexamethasone probably is not in the prevention of the development of brain ischemia itself, because dexamethasone does not reduce the volume of brain infarction. ${ }^{27}$ It seems probable that dexamethasone acts by preventing the deleterious circulatory changes which may occur secondary to the combined effects of ischemic stroke and high-dose pentobarbital treatment.

The use of glucocorticoids in circulatory shock has been reviewed recently by Lefer and Spath. ${ }^{28}$ The protective hemodynamic effects of glucocorticoids in circulatory shock are the following: a positive inotropic effect, a vasodilator action, and potentiation of the circulatory effects of catecholamines. ${ }^{28}$ These effects are not direct and can be demonstrated satisfac- 
torily only in the presence of circulatory shock. How can these factors be applied in the present study? Dexamethasone treatment in group III could have prevented the shunting of blood away from major vascular beds (e.g., fat tissue). Thus, that portion of change in the elimination rate constant due to abnormal distribution of pentobarbital after ischemic stroke might be normalized. Furthermore, maintenance of normal hepatic circulation might be accomplished by treatment with dexamethasone; by this means the intrinsic clearance of pentobarbital would be maintained. In addition, it is also possible that dexamethasone could enhance the activity of the hydroxylating enzyme directly, since glucocorticoids can enhance the actions of certain enzymes. ${ }^{29}$ All of the above hypotheses together could explain the tendency toward normalization of the altered $A U C, C l_{p}$, and $\beta$ after dexamethasone treatment in the presence of ischemic stroke.

Dexamethasone treatment did not totally correct the decreased volume of distribution $\left(V_{d}\right)$ of pentobarbital which occurred in the presence of ischemic stroke. However, although there was still a significant difference in the mean $\nabla_{d}$ of the control group (group I) and of the dexamethasone-treated stroke group (group III), there was a tendency of $V_{d}$ in group III toward that of group I. Thus, it appeared that unlike the other pharmacokinetic parameters, the decreased $\nabla_{d}$ produced by ischemic stroke was not completely corrected by dexamethasone treatment.

\section{Summary}

The values of the pharmacokinetic parameters for pentobarbital were determined in 18 cats, 12 of which were subjected to acute ischemic stroke by ligation of the left middle cerebral artery (LMCA). All 18 cats received $50 \mathrm{mg} / \mathrm{kg}$ sodium pentobarbital during operation.
The following three experimental groups were formed: control (sham-operated); ischemic stroke plus administration of 4 $\mathrm{mg} / \mathrm{kg}$ dexamethasone; and ischemic stroke without dexamethasone administration. Ischemic stroke significantly prolonged the plasma half-life of pentobarbital, but concurrent administration of dexamethasone prevented this effect. Ischemic stroke significantly reduced the plasma clearance of pentobarbital, but dexamethasone prevented this reduction. Ischemic stroke significantly increased the area under the plasma pentobarbital concentration-time curve, but dexamethasone prevented this increase. Ischemic stroke significantly reduced the volume of distribution, but dexamethasone did not prevent this reduction. The alterations of the values of these pharmacokinetic parameters for pentobarbital by ischemic stroke and reversion to normal by dexamethasone treatment are discussed in the light of certain known circulatory changes which occur secondary to ischemic stroke and dexamethasone treatment.

\section{References}

1. Smith, A. L., Hoff, J. T., Nielsen, B. L., and Larson, C. P.: Barbiturate protection in acute focal cerebral ischemia. Stroke $5: 1$ (1974).

2. Hoff, J. T., Smith, A. L., Hankinson, H. L., and Nielsen, S. L.: Barbiturate protection from cerebral infarction in primates. Stroke 6:28 (1975).

3. Black, K. L., Weidler, D. J., Jallad, N. B., Sodeman, T. M., and Abrams, G. D.: Delayed pentobarbital therapy of acute focal cerebral ischemia. Stroke 9:245 (1978).

4. Scheinberg, P., Meyer, J. S., Reivich, M., Sundt, T. M., Jr. and Waltz, A. G.: XIII. Cerebral circulation and metabolism in stroke. Stroke 7:212 (1976).

5. Subin, H., and Weil, M. H.: The mechanism of shock following suicidal doses of barbiturates, narcotics and tranquilizing drugs, with observations on the effects of treatment. Amer. J. Med. 38:853 (1965).

6. Harrison, M. J. G., and Russell, R. W. R.: Cerebral edema due to cerebral infarction in the gerbil. In Cerebral Circulation and

The Journal of Clinical Pharmacology 


\section{ISCHEMIC STROKE AND PENTOBARBITAL}

Metabolism, Lansfitt, T. W., McHenry, L. C., Reivich, M., and Wollman, H., Eds. New York, Springer-Verlag, 1975.

7. Wagner, J. G., Weidler, D. J., Hallmark, M. R., Black, K. L., and Domino, E. F.: Pharmacokinetics of pentobarbital in the cat and comparisons with the rabbit and man. Res. Comm. Chem. Path. Pharmacol. $16: 375$ (1977).

8. Smith, R. B., Dittert, L. W., Griffen, W. O., Jr., and Doluisio, J. T.: Pharmacokinetics of pentobarbital after intravenous and oral administration. $J$. Pharmacolinet. Biopharm. 1:5 (1973).

9. Ehrnebo, M.: Pharmacokinetics and distribution properties of pentobarbital in humans following oral and intravenous administration. J. Pharm. Soi. 63:1114 (1974).

10. Reidenberg, N. M., Lowenthal, D. T., Briggs, W., and Gasoaro, M.: Pentobarbital elimination in patients with poor renal function. Clin. Pharmacol. Therap. $20: 67$ (1976).

11. Sundt, T., and Waltz, A.: Experimental cerebral infarction: retro-orbital, extradural approach for occluding the middle cerebral artery. Mayo Clin. Proc. 41:159 (1966).

12. Schalm, O. W., Jain, N. C., and Carroll, J.: Veterinary Hematology, 3rd ed. Philadelphia, Lea and Febiger, 1975, p. 109.

13. Scott, P. P.: The cat. In The UFAW Handbook on the Care and Management of Laboratory Animals, Lane-Petter, W., Warden, A. N., Hill, B. F., Paterson, J. S., and Ververs, H. G., Eds. Edinburgh and London, E. and S. Livingstone, Ltd., 1967 , p. 508

14. Sedman, A. J., and Wagner, J. G.: CSTRIP, a Fortran IV computer program for obtaining initial polyexponential parameter estimates. J. Pharmaceut. Sci. 65:1006 (1976).

15. Metzler, C. M.: NONLIN : a computer program for parameter estimation in nonlinear situations. Technical Report No. 7292/69/7292/005. Kalamazoo, Mich., The Upjohn Co., Nov. 25, 1969.

16. Wagner, J. G.: Linear pharmacokinetic equations allowing direct calculation of many needed pharmacokinetic parameters from the coefficients and exponents of polyexponential equations which have been fitted to the data. J. Pharmacokinet. Biopharm. 4:443 (1976).

17. Wagner, J. G.: Fundamentals of clinical pharmacokinetics. Hamilton, Ill., Drug Intelligence Publications, 1975, p. 83.
18. Altman, P. L., and Dittmer, D. S., Eds.: Biology Data Book, Federation of American Bociety for Experimental Biology. Baltimore, Maryland, Biological Handbooks, 1974, p. 1719.

19. Weidler, D. J., Das, S. K., and Sodeman, T. M.: Cardiac arrhythmias secondary to acute cerebral ischemia: prevention by autonomic blockade. Circulation 53 and 54 (Suppl. II) :102 (1976).

20. Jallad, M. S., Weidler, D. J., and Das, S. K.: Effect of progressive ischemic stroke on plasma catecholamines. Stroke 9:96 (1978).

21. Benowitz, N. L., and Meister, W.: Pharmacokinetics in patients with cardiac failure. Clin. Pharmacokinet. 1:389 (1976).

22. Kitagawa, H., Kamataki, T., and Yashida, S.: Studies on drug metabolism. IV. Effects of high dose administration of pentobarbital and phenylbutazone on the plasma biologic half lives in various species. Chem. Pharm. Bull. 16:2320 (1968).

23. Nies, A. S., Shand, D. G., and Wilkinson, G. R.: Altered hepatic blood flow and drug disposition. Clin. Pharmacokinet. 1: 135 (1976).

24. Brodie, B. B., Burns, J. J., Mark, L. C., Lief, P. H., Bernstein, E., and Papper, E. M.: The fate of pentobarbital in man and $\operatorname{dog}$ and a method for its estimation in biologic material. J. Pharmacol. Exp. Therap. 109:26 (1953).

25. Kitagawa, H.: Studies on drug metabolism. I. Effect of respiratory oxygen on the duration of pentobarbital induced sleep. Chem. Pharm. Bull. 16:1589 (1968).

26. Harrison, M., and Russel, R.: Effect of dexamethasone on cerebral infarction in the gerbil. J. Neurol. Neurosurg. Psychiat. 35:520 (1972).

27. Myoung, L. C., Mastru, A., and Waltz, A.: Ineffectiveness of dexamethasone for treatment of experimental cerebral infarction. Stroke 5:216 (1974).

28. Lefler, A. M., and Spath, J. A., Jr.: Pharmacologic basis of the treatment of circulatory shock. In Cardiovascular Pharmacology. Michael, J. A., Ed. New York. Raven Press, 1977.

29. Baxter, J. D., and Forsham, P. H.: Tissue effects of glucocorticoids. Amer. J. Med. 53:573 (1972).

Reprint requests to: Dr. D. J. Weidler, Division of Clinical Pharmacology, Department of Pharmacology (D7-3), University of Miami School of Medicine, P.O. Box 015996, Miami, Fla. 33101. 